\title{
El cólera en Chile (1886-1888)
}

\author{
ENRIQUE LAVAL R.
}

\section{Cholera in Chile (1886-1888)}

"Cuando apareció el cólera, la sociedad tembló de miedo. Se tomaba todo género de medidas, hasta las más absurdas, y era tal la ignorancia reinante, que según contaba Vicente Grez, una dama enloquecida de terror, se presentó a la Cordonería Alemana pidiendo diez varas de cordón... sanitario". (Memorias del Tiempo Viejo. Luis Orrego Vicuña. Ed. Univ. de Chile. 1984. Stgo. de Chile).

"Revuelo provocó en Santiago la noticia de la llegada del diputado don Guillermo Puelma Tupper, quien rompiendo el cordón sanitario regresó desde la Argentina, por un paso del sur. El diputado quedó aislado y sólo se permitió la visita de su padre y de su hermano, el doctor Francisco Puelma Tupper. Se dispuso que se fumigara y que sólo podría irse a su casa aislado por dos días, ocupando sólo las dependencias de altos. El señor Puelma Tupper, salió de Mendoza, el día 9 del corriente, cuando no había todavía ningún caso de cólera en la ciudad, Anduvo por la cordillera caminando sin cesar durante once días, permaneciendo tres noches sin dormir, hasta que llegó a Chile, pasando a caballo a Chillán. El señor Puelma Tupper vino cambiándose y botando ropa durante todo el trayecto, hasta el punto de llegar sin equipaje, y se dio cuatro fumigaciones". ("El Mercurio" de Valparaíso, miércoles 22 de diciembre de 1886).

El cólera había aparecido el 1 de octubre de 1886 en el barrio de la Boca en Buenos Aires; rápidamente se difundió en la capital y de ahí se propagó a Rosario, Córdoba y Santa Fe. En Mendoza los primeros casos aparecieron el 7 de noviembre y el pánico se apoderó de la población. Sus habitantes huyeron en todas direcciones, llegando algunos a Chile y el 25 de diciembre se inició la epidemia en la villa de Santa María, cercana a San Felipe1. "Los vecinos de dicho pueblo echaron a correr que, furtivamente, por las Cuevitas, camino extraviado de la cordillera, habían visto al argentino Eloy González, atravesando en compañía de su criado Jerónimo Álvarez, el que enfermó de cólera, murió y dejó la epidemia en nuestro país"’. Dos o tres días más tarde se denunciaron casos en la misma ciudad de San Felipe, en La Calera, Quillota, quedando todo el valle de Aconcagua contaminado"1, 3

Se conocen las epidemias de cólera de 1830, 1846, 1865 y 1883. La de 1830 por vez primera invadió Europa, en Astrakán en 1823, principiando en Bengala en 1817. Desde ella se estuvo escribiendo en los periódicos chilenos con temor de que nos invadiera, junto con la fiebre amarilla. Don Andrés Bello fue quien por primera vez, comenzó a publi- car en El Araucano sobre escarlatina y cólera, diciendo en uno de sus artículos: "el cólera no es probable que se presente en Chile, atravesando mares inmensos, ni que aparezca en el interior antes de haber visitado los puertos. Si este azote ha de recorrer la tierra, será Chile, según el orden natural, uno de los últimos países que lo sufran. Nuestro comercio es limitado; nuestra población escasa y esparcida; y si aparece en un punto, hay aquí más facilidad para aislar el mal y atajar sus progresos que en la mayor parte de las otras naciones del globo"2.

No obstante los cordones sanitarios, medida tan inútil como costosa y de confianza engañosa, el cólera adquirió alarmantes caracteres epidémicos: llegó a Valparaíso y el 15 de enero de 1887 estalló en Santiago, en el barrio de Barrancas. A fines de dicho mes se había extendido no sólo a toda la ciudad sino a todo el departamento y aun a Melipilla. En los primeros días de febrero hizo su aparición en Rancagua y Rengo.

Al terminar 1887, el cólera se había propagado por el norte hasta Freirina y por el sur hasta Valdivia. En marzo de 1888 llegó a Copiapó, pero ya en este mes la intensidad de la epidemia comenzó a declinar y el último caso se presentó en Ovalle, el 2 de julio de 1888.

Con el objeto preciso de asegurar la necesidad de acción y el cumplimiento de las medidas que se adoptaron para evitar la propagación del cólera, el gobierno creó el 7 de enero 1887 un comité ejecutivo para Santiago, el que estuvo integrado por el intendente, que lo presidía, el Ilmo. y Rvdmo. Sr. arzobispo de Santiago, el primer alcalde, el presidente de la Junta de Beneficencia, el decano de la Facultad de Medicina, el Superintendente del Cuerpo de Bomberos y tres vecinos. Es curioso anotar que en un comité ejecutivo de medidas sanitarias, compuesto de nueve miembros, uno sólo fuera médico, el doctor José Joaquín Aguirre, decano de la Facultad de Medicina.

Este comité estableció en Santiago tres lazaretos: el del oriente o de la Maestranza, a partir del 20 de febrero de 1887 y que funcionó durante sesenta días en el Hospital San Francisco de Borja, a cargo del doctor Manuel Francisco Aguirre; el lazareto del sur o del Camino de Cintura, bajo la dirección médica del doctor Francisco Aguirre y administrado por don Miguel del Fierro, que estuvo abierto durante sesenta y siete días y del poniente o de Matucana, en actividad por cuarenta días, bajo la supervigilancia del doctor Cornelio Guzmán.

Al iniciarse el otoño, la epidemia declinó en el centro del país, desapareciendo totalmente durante 
el invierno, pero en el mes de octubre se recibieron en los tres hospitales de Santiago 93 coléricos, y como la enfermedad continuara difundiéndose otra vez más, el gobierno adoptó nuevas medidas ( $s e-$ gunda epidemia) ${ }^{1}$.

Un decreto supremo cursado el 16 de noviembre de 1887 creó una comisión directiva del Servicio Sanitario del Cólera, presidida por el doctor Wenceslao Díaz Gallegos ${ }^{4}$, y encargada de la dirección superior del servicio para combatir el cólera en todo el país. En Santiago sólo efectuó la atención domiciliaria, ya que el gobierno confió a la Junta de Beneficencia de la capital la dirección de los lazaretos establecidos o por establecerse, el transporte a ellos de los enfermos, la conducción y sepultación de los que fallecieran, ya en un cementerio de coléricos llamado Higueras Zapata, que una vez terminada la epidemia fue clausurado, o en los nichos construidos ad hoc en el General y, finalmente, el cuidado de suministrar alimentos adecuados a los convalecientes de cólera. ${ }^{5,12}$

La comisión directiva en vista del fracaso, en la llamada primera epidemia, de la clausura de los boquetes y pasos cordilleranos, de los cordones sanitarios y estaciones de cuarentena, en esta denominada segunda epidemia, eliminó totalmente dichas medidas, concentrando todos sus esfuerzos en el tratamiento de los enfermos.

Como se mencionó más arriba, en octubre de 1887 se atendieron en los hospitales de Santiago 93 enfermos y en noviembre la cifra se elevó a 573 , en diciembre aumentó a 674, declinando en enero de 1888 a 535 , en febrero a 330 , en marzo a 85 ; a 3 y 1 , en abril y en los primeros diez días de mayo, respectivamente.

Para la atención de los enfermos de la segunda epidemia, se acordó establecer cuatro lazaretos, con una cabida máxima de 80 enfermos cada uno.

El primero se abrió el 12 de noviembre de 1887 en los galpones del sector Maestranza del Hospital San Francisco de Borja, a cargo de su administrador don Blas Vial. El segundo inició sus actividades a mediados del mismo mes, en el edificio que para la anterior epidemia se había construido dentro del actual Hospital San José, que en aquella época era un simple lazareto de variolosos, a cargo de su administrador el Prebendado don Juan Achurra. El tercer lazareto funcionó en la avenida sur del Camino de Cintura (hoy avenida Matta). Se proyectó un cuarto a cargo de don Pedro Félix Salas, pero no fue posible ponerlo en marcha, por no haberse encontrado un local adecuado. ${ }^{1}$

Cada lazareto fue servido por dos médicos, cada uno con $\$ 400$ mensuales; cuatro estudiantes de medicina, con $\$ 200$ mensuales los de sexto año y con $\$ 150$ los de cuarto y quinto año; un boticario con $\$ 100$ al mes y empleados de servicio: \$25 mensuales los hombres y \$20 las mujeres.

El transporte de enfermos se efectuaba mediante carretelas que esperaban en distintos puntos de la ciudad. Además se contó con una ambulancia de los señores Matte, con otras de la comisión directiva y con tres coches que la municipalidad confió a diversos cuarteles de policía ${ }^{6}$.
En la primera etapa de la epidemia se asistieron en los hospitales y lazaretos de Santiago 2.140 enfermos, y en la segunda, 2.095. Refiriéndose a esta segunda el presidente de la Junta de Beneficencia de Santiago, don Blas Vial, decía al ministro del interior: "a fines de diciembre y a principio de enero comenzó a notarse que el uso inmoderado de la fruta y de las legumbres, con especialidad el de la sandía, el del tomate y el del maíz, era en la generalidad de los casos, la causa determinante de la enfermedad, causa que fue, todavía más pronunciada, en los meses siguientes de febrero y marzo"

Se conservan datos muy exactos del tratamiento de los coléricos en los lazaretos de Santiago. La terapia era diversa según el período de la enfermedad. Clásicamente se reconocían en su evolución tres períodos: de diarrea premonitoria, de cólera declarado y un tercer período o álgido y asfíxico. En el $90 \%$ de los casos, el cólera se iniciaba con crisis diarreicas. Si se estimaba que había ocupación de vientre y la lengua estaba saburral, se administraban 30 a 50 centígramos de calomel, seguidos, una hora más tarde, de 25 a 30 gramos de aceite de castor. Este último, "libre de las impurezas del ricino, es simplemente un laxante, una escoba que barre con las materias extrañas contenidas en el intestino". Si la diarrea persistía, se trataba con láudano y en caso de continuar, con baños calientes y enteroclisis de Cantani. Cuando en 1884 estalló cólera en la ciudad de Nápoles, donde el doctor Arnaldo Cantani era profesor de Clínica Médica, utilizó aquel procedimiento y según su experiencia "la enteroclisis tánica caliente, astringe, calienta, excita, es antiséptica y combate también las fermentaciones anormales, da agua a la sangre por aquellas partes de la mucosa intestinal que aún absorbiendo - y como lo demostró Manfredi por invitación mía - esteriliza el bacillus virgula, impidiendo su multiplicación, aunque no lo mata"s.

Los baños duraban 10 a 15 minutos, a $39^{\circ}-40^{\circ} \mathrm{C}$. "De esta manera se produce un estimulo general, viene la diaforesis, siente el enfermo un bienestar muy grande y generalmente desaparece la diarrea.

También se atenúa el catarro y disminuye la absorción del veneno colerigeno" 10 .

En el segundo periodo o de cólera declarado, los síntomas a tratar eran la diarrea riciforme, los vómitos y los calambres. La enteroclisis era el tratamiento de elección para la diarrea, inyectándose 3 a 5 litros de una solución de tanino al $5 \%$, a la temperatura de $38^{\circ}-40^{\circ} \mathrm{C}$ o con polvos de algarrobilla. Para los calambres se usaban fricciones secas o con mostaza y trementina.

Los vómitos eran tratados con hielo, ingerido pequeños trozos; píldoras de hielo, poción de Rivière helada, champaña helada, agua de Seltz simple o con doble carga de ácido carbónico, pociones con cocaína, etc.

Pero, si ni los vómitos ni la diarrea desaparecían, se llegaba al tercer período de algidez:: el enfermo está frío, la nariz afilada, los ojos desencajados, la voz apagada, el pulso filiforme. En este instante se usaban en nuestros lazaretos los estimulantes tóni- 
cos y difusibles, especialmente esta poción:

agua de canela......... $500 \mathrm{~g}$

licor de Hoffman....... $10 \mathrm{~g}$

tintura de almizcle..... $5 \mathrm{~g}$

jarabe de menta........ $40 \mathrm{~g}$

Por cucharadas cada media hora, adicionada con trocitos de hielo. Si los vómitos no habían reaparecido, se daba licor de ajenjo, sobre todo en los alcohólicos. Por vía rectal se continuaba colocando enemas de $100 \mathrm{~g}$ de vino caliente con $2 \mathrm{~g}$ de éter.

La vía hipodérmica no era despreciada: inyecciones de alcohol, éter alcanforado, citrato de cafeína. Pero era un tratamiento de elección. "Se sabe que uno de los graves accidentes del cólera es el espesamiento de la sangre por las perdidas acuosas que ha sufrido el organismo (aunque también se ven asfixias mortales, sin que haya habido grandes pérdidas serosas)". "Cuando la asfixia proviene del espesamiento de la sangre, teóricamente la hipodermoclisis está indicada y los resultados que nos ha producido la práctica confirman plenamente la teoría" 7,10 . Se inyectaban soluciones de cloruro de sodio al $5 \%$, combinado con sulfito de sodio al $10 \%$, o bien, de hiposulfito de sodio al $3 \%$, con carbonato neutro de soda al $3 \%$.

Excepcionalmente se utilizaba la vía intravenosa, porque con la fleboclisis, como decía el doctor Wenceslao Díaz, "los enfermos han vuelto a la vida por un momento, pero luego ha sobrevenido abatimiento y la muerte"5. Pero dicha vía encontró partidario fervoroso en el doctor Francisco Aguirre, médico jefe del lazareto sur, empleando una solución de agua filtrada hervida (dos litros), más cloruro e hiposulfato de sodio. "A los dos o cinco minutos después de la inyección, aparecen escalofríos generalizados, contracciones fibrilares de los músculos pectorales y la piel toma el aspecto de carne de gallina. Estos fenómenos se han producido en la generalidad de los casos. Después el enfermo se tranquiliza y duerme",

La medida heroica en este período era la peritoneoclisis, practicada por primera vez en el país, cuando aún en Europa no se la utilizaba. "Nada tiene de extraño que se haya recurrido a esta operación, atrevida a primera vista, si se considera que en el último período de la algidez y principio de la asfixia cuando se han agotado todos los otros recursos, el médico se encuentra desarmado y el enfermo va a morir irremediablemente. La práctica ha correspondido a la teoría, pues han salvado algunos enfermos y a otros se les ha prolongado la vida" ${ }^{\text {. }}$.

Recordemos que durante la epidemia de cólera se utilizó el conocido licor del Padre Delaunay, inventado por este sacerdote lazarista, compuesto de láudano de Sydenham, esencia de menta, alcohol y jarabe.

Poco a poco se fue apagando esta epidemia de cólera, que asoló a varias provincias del territorio nacional. A raíz de lo sucedido, el gobierno creó el 19 de enero de 1889 el Consejo Superior de Higiene Pública. El proyecto presentado por el doctor Corbalán Melgarejo sirvió de base para la redacción de la ley que el 15 de noviembre de 1892, dio estructura definitiva a este Consejo. Aun cuando continuó únicamente como un organismo consultivo, esa ley tuvo la ventaja de permitir la creación del Instituto de Higiene, que tantos servicios prestó a la comunidad y que con el correr de los años se transformó en el Instituto Bacteriológico, hoy Instituto de Salud Pública ${ }^{4}$.

¿Cuántas vidas cobró la epidemia? "La aparición del cólera motivó un sorpresivo y arduo trabajo de los sepultureros en 1886 y años siguientes. Según datos del registro civil, 23.432 personas murieron víctimas de esta enfermedad, lo que era bastante para una población de 3 millones"11,12. El doctor Adolfo Murillo estimó en aproximadamente 40.000 el número de fallecidos en todo el país ${ }^{2}$.

En la campaña del cólera, participaron 200 médi$\cos$ y 100 estudiantes de medicina. Una amarga crónica del doctor David Benavente en 1888, transcrita por Claudio Costa-Casaretto ${ }^{2}$, termina: "Y así se dirá después que se ha premiado con largueza a los jóvenes que sirvieron el cólera, que hicieron poco trabajo y costaron demasiado caro a la nación. Y es muy posible que así suceda, aunque se ignore lo que se habla, porque, como ha dicho con desaliento un colega español, tiempo llegará en que se irá hasta decir a la ciencia: ya te contentarás con des pesetas. Y en verdad la profecía amenaza cumplirse".

\section{Bibliografía}

1.- Laval M E. Historia del hospital San Francisco de Borja de Santiago (inédito).

2.- Costa-Casaretto C. La Revista Médica de Chile 100 años atrás. Año XVII, Nº 4. octubre 1888. Rev. Méd. Chile 1989; 117: 228.

3.- Góngora E A, Osorio V J. La sociedad frente a la muerte. La epidemia de cólera en Chile. 1886-1888. Memoria para optar al grado de Licenciado de Historia. Universidad Católica de Valparaíso. Instituto de Historia. Chile. 1978.

4.- Laval M E. Noticias sobre los médicos en Chile. S. XIX. Tomo II. Ed. Historia Médica. Sigo. de Chile. 972.

5.- Díaz G W. Memoria de la comisión directiva del Servicio Sanitario del Cólera, presentada al Sr. Ministro del Interior Santiago, 1888.

6.- Memoria que el director del lazareto de coléricos del Camino de Cintura pasa a la Junta Departamental de Salubridad Impta. Nacional. Stgo. de Chile. 1887.

7.- Informe de los médicos de lazaretos sobre el tratamiento del cólera". Rev Méd de Chile. Febrero-marzo. 1887. p. 341.

8.- Tratamiento del cólera asiático por la enteroclisis: su acción fisiológica. Anales de la Univ. de Chile. 1888. p. 186.

9.- Aguirre F. Informe sobre inyecciones intravenosas Rev. Méd. Chile. Febrero-marzo. 1887, p. 386.

10.- Informe de los médicos de lazaretos sobre el tratamiento del cólera asiático, presentado a la Junta de Salubridad. Impta Nacional. Stgo. de Chile. 1887.

11.- Vida y milagros del Cementerio General. El Mercurio de Santiago. 2 de noviembre de 1985.

12.- Osses D. La historia infausta. Vida Médica 1987; 39; 6. 